\title{
Learning Styles and Self-regulation: An Associational Study on High School Students in Iran
}

\section{Ehsan Safari}

MA student in TEFL, Department of English, Roudehen Branch, Islamic Azad University, Roudehen, Iran Email: Ehsan.safari32@gmail.com

\section{Mahshid Hejazi}

PhD, Faculty member, Department of English, Mashhad Branch, Islamic Azad University, Mashhad, Iran Corresponding Author Email: mahshidhejazi1920@yahoo.com;mhejazi1971@gmail.com

\section{Doi:10.5901/mjss.2017.v8n1p463}

\section{Abstract}

\begin{abstract}
Self-regulation plays an important role in academic circumstances. If a learner wants to be called a self-regulated person, he or she should independently plan, monitor, and evaluate his or her own learning. Some students possess these properties subconsciously and some others do not. This study is aimed at investigating the relationship between different learning styles and self-regulation on the third grade high school students in Mashhad. The participants were 155 high school students. The Data collection instruments which were used in this study were Kolb's learning styles questionnaire (LSI) (1976) and Pintrich, \& De Groot (1990) self-regulation inventory. They were used to examine the relationship between the four learning styles that are converging, diverging, assimilating, and accommodating with the participants' self-regulation. The results showed that there is a positive relationship between each learning style and self-regulation. They also showed that the participants who practiced converging and assimilating learning styles were more self-regulated as compared with those who practiced diverging and accommodating learning styles.
\end{abstract}

Keywords: converging, diverging, assimilating, and accommodating learning styles, self-regulation

\section{Introduction}

Nowadays, being educated is vital for having a better life. Besides, silent and rapid changes of science and technology encourage people to become more up to date in terms of their knowledge to be in harmony with the revolutions and to modernize their own skills (Dasta, 2007). One of the learning obstacles in classroom is the lack of coordination between the educator's instructing method and the learner's acquiring styles and that is why different teaching methods are applied. Using different teaching methods are supposed to be based on the principles which are at least in line with most of the students' learning styles in each class or course (Dobson, 2009). Several studies emphasize (Brown, 2007 and Kolb, 1984) the interpretation of different learning styles that could be considered as a good way for educators to get a better understanding of their own learners' learning. This information can be applied as a better guidance in selection of an appropriate method which is employed in the classroom. Indeed, few studies have examined the description and identification of the components of learning styles which had been used by students (Norman, 2009). Meantime, the concept of self-regulation or self-adjustment in psychology and teaching has taken an important place, since emphasis on this concept introduces a procedure which enhances the learner's role in learning process. To give voice to this claim, in recent years, several programs have been developed through which self-regulation can be taught to students. One of the successful education programs of self-regulation is the cognitive-behavioral change. Cognitive-behavioral change program consists of elements of behaviorism and also cognitivism. In self-regulation program which depends on cognitive-behavioral change, fourfold skills are taught for the purpose of determination, control on self-behavior and evaluation of self-behavior and personal premium in order to make the learning an accepted ability for the learners.

\section{Review of Literature}

Different factors can influence the process of learning. Some of them are related to learners' characteristics that are in accordance with social learning contexts. Skinner believed that a real and effective educational system cannot be created 
without knowing the operation of learning and teaching. Learning styles are different among individuals and it can be defined as a method that new information and experiences are organized and processed in human mind. Different ideas were propounded about learning styles. For example, context-dependent learning and context-independent learning, rapid and meditative learning, minor and major learning, deep and surface learning, active and thoughtful learning, and theoretical and practical learning are considered to be examples of learning theories.

Kolb's learning styles' model and his experiential learning theory emphasized the role of experience in learning. Kolb also proposed that people had different learning styles. Kolb's learning theory sets out four distinct learning styles each of which consists of a four stage learning cycle. The first stage is called Concrete Experience in which the learner enters into a new experience perfectly and without bias. In other words learning happens through experience. The second stage is called Observation and Reflection through which the subject is observed from different aspects and the learner is trying to find out the meaning of things. Abstract Concept is considered as the third stage in which the learner is attempting to make logical analysis of ideas for a better understanding of situation. In the last stage which is called Active Experimentation, the learner can apply his or her own hypothesis in order to solve the problems and make his or her own decisions. According to Kolb (1984) all students should pass these stages and this cycle replicates until the learning process is completed. The important point is that all learners cannot succeed in all the stages as compared to other parts. Kolb (1984) also believes "learning is the process whereby knowledge is created through the transformation of experience"(p. 38).

Kolb (1984) proposed four learning styles which are converging, diverging, assimilating, and accommodating based on his own studies. Meanwhile, self-adjustment or educational self-regulation is one of the basic learning subjects which seems to be in touch with metacognition. In comprehensive definition, this kind of learning is defined as organized and active process which learners choose and try to control and monitor their motivation and behavior. The attention of teachers and programmers to different levels of education and toward learning styles causes that education and learning process being more facilitated and helps the learners being disciplined for selecting the job situation. A standard definition of learning style is used for cognitive, emotional and social psychological definite behaviors which can be applied as rather consistent index in understanding, interaction and reaction toward learning surroundings. Another definition of learning style includes the composition of cognitive, emotional and physiologic methods that learners use for retrieval, organization and reminding of information (Peters, 2009). Learning styles are defined as one of the successful factors in academic educations (Brown, 2007). If the learners are well aware of their learning styles, they will tend not to be bored and distracted in the class. Also they do their best on the tests and do not get discouraged about the course; therefore the familiarity of the subject and motivation will happen (Felder \& Silverman, 1988; Goldleski, 1984).

Those researches which had been concerned about theories of learning have created a variety of methods to classify learning styles, but nowadays, there is no acceptable classification for learning styles so various categories and scales are used (Dobson, 2009). Most of these scales and classifications have some features in common and they emphasize on environment preferences, emotional and perceptional conditions, individual differences and cognitive styles. Learning styles scales can measure different features like individual differences, extrinsic and intrinsic motivation, and male-cognitive tactics (Peters, 2009). The lack of useful framework for learning styles' theories and their measurement is a strong criticism. In 2004, England learning studies and skills center published a report about systematic models and available instruments concerning learning styles. In this report, different items expressed the lack of coordination between models, instruments and trainers in regard to learning styles. (Romanelli, 2009). On the other hand, many researchers discuss the importance of the awareness of learning styles for both teachers and students. The teachers or instructors, who are knowledgeable enough about styles, can match their own teaching with students' learning styles. Similarly, the students can distinguish their own different styles in order to learn better.

One of the famous scales concerning learning styles is Kolb's checklist. Although different results are published regarding the usage of this scale, the related studies are demonstrative of the coherence between this scale and learning theories ( D'amore, James \& Mitchell, 2011). Kolb (1984) is one of the educational theorists who proposed a cycle regarding the learning styles. David Kolb and Alice Kolb (2005) noticed that "the concept of learning style describes individual differences in learning based on the learner's preferences for employing different phases of the learning cycle. Because of our hereditary equipment, our particular life experiences, and the demands of our present environment, we develop a preferred way of choosing among the four learning modes" (p. 4). Each four Kolb's learning styles is related to a special stage of learning cycle. Kolb (1984) divided that cycle into four-type definition of learning styles. A learner with diverging learning style is the one whose checklist scale results lay between tangible experiences and reflexive observation. Those with such learning styles are thoughtful and have a strong imagination. They are trying to watch rather than do and interact with others and consider one experience or event from different aspects. They also prefer to be in groups. One of the weaknesses of diverging learning style is that they hardly select things and they have also 
difficulties in concentration. A converging learner is the one whose score is between abstract conception and active experience. These learners apply practical ideas and also they are considered as problem solvers and decision makers. They prefer to work with things instead of people and tend to make quick decisions. Assimilating learner is one whose checklist results lay between reflexive observation and abstract conception. Although people with assimilating learning style do not always have applied ideas, they can create models and theories about their own real experiences. These learners prefer to participate in learning by studying, listening, observing and reflecting. Accommodating learner is the one whose mark is between real experiences and active experiences. These people look for venturesome and act-based opportunities. They enjoy trial and error and consider learning experimentally (Kolb, 1984). Kolb (ibid) proposed that when explaining how to use this model for learning, one should consider that all people may not have similar skills in applying each four learning styles. None of these styles has advantages over others and no one is considered directly as the one with a better intelligence or performance. The identification of students' learning styles makes them capable of understanding their strengths and weaknesses. For example, people who like to employ an 'accommodating' learning style are those who are not inclined to be told to apply lots of directions and rules, in such ways they will get disappointed (Kolb, 1984).

Self-regulation is one of Banduara's cognitive-social conceptions. In most cases, self-regulation is a kind of learning which is disciplined by metacognition, strategic action, and motivation to learn (Bulter \& Winne, 1995; Winne \& Perry, 2000). The importance of self-regulation had been mentioned by Man-Chih (2006). He stated that self-regulation should be considered as an integration process because learners are capable to discipline their own learning, motivation, and behavior. Man-Chih (2006) believed that "self-regulated learning is an innovative approach to promote a sense of belonging, and it provides students with a role in decision making and offers a supportive approach to learning" (p.34). Furthermore, he indicated that if students be aware of self-regulation, they will achieve the goals more appropriately. Additionally, a study which had been conducted by Lavasani, Mirhosseini, Hejazi, and Davoodi (2011) emphasized on the benefits of self-regulation in the process of learning. They also claimed that "self-regulated learners are more active participants in the process of learning" (p.630). Moreover, self-regulated learners put meta-cognition strategies into practice in order to get advantage of the learning process (Lavasani et al, 2011). A study done by Rakes and Dunn (2010) revealed that self-regulation has great impact on procrastination. They claimed that "as intrinsic motivation to learner and effort regulation decreases, procrastination increases" (p. 86). Rakes and Dunn (2010) also believe that those student who do not pay attention to self-regulation, they will be faced with difficulty in learning, especially in online classes in which they must figure the lessons out. Ormrod (2009) stated that "self-regulation is a process of taking control of and evaluating one's own learning and behavior" (p. 105).

People who acquired self-regulation are able to be autonomous in learning processes. They put emphasis on monitoring, directing, and regulating actions in order to achieve goals, increase ability, and improve knowledge (Paris \& Paris, 2001). In particular, the familiarity of mental and psychological abilities and strategies in academic activities become well-known in self-regulated learners and they are able to put into use those strategies to different practices and tasks which they face (Dweck \& Legget, 1988; Dweck, 2002). Those learners who are self-regulated believe that success in learning occurs when a person always keeps practicing, having well-known understanding of topics, and putting hard effort (Perry, Phillips \& Hutchinson, 2006). In addition, if one learner carries such characteristics, he or she will be considered as a student with high self-efficacy (Pintrich \& Schunk, 2002). Finally, self-regulated learners can get advantage of their own learning because they know how to apply the acceptable actions in order to reach the goals.

This study is conducted based on a number of hypotheses that are:

1. There is no relationship between accommodating learning styles and the students' self-regulation.

2. There is no relationship between converging learning styles and the students' self-regulation.

3. There is no relationship between diverging learning styles and students' self-regulation.

4. There is no relationship between assimilating learning style and the students' self-regulation.

\section{Methodology}

\subsection{Participants}

The participants of the present study were 155 out of 735 female high school students in Mashhad. The English language proficiency level of these students was lower intermediate and they were chosen by simple cluster sampling method. 


\subsection{Instruments}

Kolb's (1976) questionnaire is used for data collection and learning style designation. This questionnaire is designed to show that how students learn. In this questionnaire, there is no right or wrong answer and all options are acceptable. The questionnaire has twelve questions which are classified into the categories of: concrete experience, reactive observation, abstract conception and active experiment that each evaluates one aspect of a person's capability. From deliberative observation, two marks are gained. These two marks are placed on coordinate axis one of them is on vertical axis AC-CE (abstract conception, concrete conception) and the other one is on the horizontal axis DO-AE (Deliberative observation, active experiment). These two coordinate axis, constitute four quadrants of a square and these quadrants show learning style (Gibbs, 2010). Pintrich and De Groot (1990) self-regulation questionnaire is used for self-regulation that its alpha Cronbach calculated as 0/83, 0/89 and 0/93 for cognitive, meta-cognitive and resource management respectively.

\subsection{Procedure}

For each question of the questionnaire there are five options and the researcher explains the questionnaire to the students that they need to read the test carefully and select the best option that matches their personality; therefore, learners should choose one of them. The students can gain a maximum of five and at least one score because the first option has one mark and the second one has two mark up to the end. The correlation method is used for analyzing the results because the concern of this study is only the comparative analysis and their relationships.

\section{Results}

As was mentioned earlier, there are four hypotheses in this study. In order to examine each hypothesis primarily the descriptive statistics of each learning style and self-regulation is displayed then the correlation between each learning style and self-regulation is assessed.

4.1 Research hypothesis 1: "There is no relationship between accommodating learning style and the students' selfregulation".

Table 1: The Descriptive statistics of Accommodating learning style and self-regulation

\begin{tabular}{|c|c|c|c|}
\hline & Mean & Standard deviation & Frequency \\
\hline Accommodating learning style & 5.95 & 1.068 & 41 \\
\hline Self-regulation & 3.92 & 0.711 & 41 \\
\hline
\end{tabular}

Table 1 displays the mean, standard deviation and the frequency of the scores for accommodating learning style and selfregulation.

Table 2: The correlation coefficient between accommodating learning style and self-regulation

\begin{tabular}{|c|c|c|c|}
\hline & & Accommodating & Self-regulation \\
\hline \multirow{2}{*}{ Accommodating. } & Correlation of Pearson & 1 & 0.458 \\
\cline { 2 - 4 } & Confidence level & 0 & 0.01 \\
\hline \multirow{2}{*}{ Self-regulation. } & Correlation of Pearson & 0.458 & 1 \\
\cline { 2 - 4 } & Confidence level & 0.01 & 0 \\
\hline
\end{tabular}

The information in table 2 shows that the correlation coefficient between accommodating learning style and selfregulation at confidence level of $0 / 01$ is $0 / 458$. It can be concluded this correlation coefficient is significant when the confidence level is above \%1. Therefore, null hypothesis 1 is rejected and there is a positive relation between accommodating learning style and self-regulation. 
4.2 Research hypothesis 2: "There is no relationship between converging learning style and the students' selfregulation".

Table 3: The Descriptive statistics of Converging learning style and self-regulation

\begin{tabular}{|c|c|c|c|}
\hline & Mean & Standard deviation & Frequency \\
\hline Converging learning style & 3.410 & 0.874 & 67 \\
\hline Self-regulation & 3.494 & 0.869 & 67 \\
\hline
\end{tabular}

Table 3 displays the mean, standard deviation and the frequency of the scores for converging learning style and selfregulation

Table 4: The correlation coefficient between converging learning style and self-regulation

\begin{tabular}{|c|c|c|c|}
\hline & & Converging. & Self-regulation. \\
\hline \multirow{2}{*}{ Converging } & Correlation of Pearson & 1 & 0.355 \\
\cline { 2 - 4 } & Confidence level & 0 & 0.01 \\
\hline \multirow{2}{*}{ Self-regulation } & Correlation of Pearson & 0.355 & 1 \\
\cline { 2 - 4 } & Confidence level & 0.01 & 0 \\
\hline
\end{tabular}

The information in table 4 shows that the correlation coefficient between converging learning style and self-regulation in $0 / 01$ confidence level is 0/355. It can be concluded that the correlation coefficient is significant above $\% 1$ level. Therefore the second null hypothesis is rejected and there is a positive relationship between the converging learning style and selfregulation

4.3 Research hypothesis 3: "There is no relationship between diverging learning styles and the students' selfregulation".

Table 5: Descriptive statistics of Diverging learning style and self-regulation

\begin{tabular}{|c|c|c|c|}
\hline & Mean & Standard deviation & Frequency \\
\hline Diverging learning style & 7.23 & 1041 & 65 \\
\hline Self-regulation & 3.96 & 0.53 & 65 \\
\hline
\end{tabular}

Table 5 displays the mean, standard deviation and the frequency of the scores for diverging learning style and selfregulation.

Table 6: The correlation coefficient between diverging learning style and self-regulation

\begin{tabular}{|c|c|c|c|}
\hline & & Diverging. & Self-regulation. \\
\hline \multirow{2}{*}{ Diverging. } & Correlation of Pearson & 1 & 0.515 \\
\cline { 2 - 4 } & Confidence level & 0 & 0.01 \\
\hline \multirow{2}{*}{ Self-regulation. } & Correlation of Pearson & 0.515 & 1 \\
\cline { 2 - 4 } & Confidence level & 0.01 & 0 \\
\hline
\end{tabular}

The information in table 6 indicates that the correlation coefficient between diverging learning style and self-regulation at $0 / 01$ confidence level is 0/515. It can be concluded that the correlation coefficient is significant above $\% 1$ level. Therefore the third null hypothesis is rejected and there is a positive relationship between diverging learning style and selfregulation. 


\subsection{Research hypothesis 4 is 'There is no relationship between assimilating learning style and the students' self-} regulation".

Table 7: Descriptive statistics of Assimilating learning style and self-regulation

\begin{tabular}{|c|c|c|c|}
\hline & Mean & Standard deviation & Frequency \\
\hline Assimilating learning style & $4 / 84$ & $0 / 439$ & 41 \\
\hline Self-regulation & $3 / 04$ & $0 / 880$ & 41 \\
\hline
\end{tabular}

Table 7 displays the mean, standard deviation and the frequency of the scores for assimilating learning style and selfregulation.

Table 8: The correlation coefficient between assimilating learning style and self-regulation

\begin{tabular}{|c|c|c|c|}
\hline & & Assimilating. & Self-regulation. \\
\hline \multirow{2}{*}{ Assimilating. } & Correlation of Pearson & 1 & 0.305 \\
\cline { 2 - 4 } & Confidence level & 0 & 0.05 \\
\hline \multirow{2}{*}{ Self-regulation. } & Correlation of Pearson & 0.305 & 1 \\
\cline { 2 - 4 } & Confidence level & 0.05 & 0 \\
\hline
\end{tabular}

The information in table 8 shows that the correlation coefficient between assimilating learning style and self-regulation at $0 / 05$ confidence level is 0/305 It can be concluded that the correlation coefficient is significant above \%1 level. Therefore the null hypothesis is rejected and there is a positive relationship between assimilating learning style and self-regulation.

\section{Discussion and Conclusion}

This research aimed at investigating the relationship between different learning styles and self-regulation on third grade high school students in Mashhad. On one hand, in the process of learning the recognition of learning styles seems to be very important and considering the matter that there is no preference on learning styles, a person can recognize his or her learning style strengths and weaknesses then try to enforce or modify them. By awareness of teaching style and learning one can improve the educators' capabilities in meeting the learners' learning needs and provide opportunities for the usage of useful guidelines and better evaluation of their performance. When there is a coincidence between learning and teaching style, it can bring better usage of time, resources and available capacities and create efficient and enjoyable experiences. The coordination and agreement between a learner's style and tasks' style has been considered as an important factor in one's success and inconsistency between a person's learning style and educational style can be the reason of a person's incapability in learning. Not paying enough attention to the styles in different situations can lead to ignorance of best talents and potential capitals. On the other hand Self-regulation is one the most important factors which would have effect on students learning and academic functions in classes. Because self-regulated learners try to adapt their mental abilities with those activities which are related to the assigned activities.

The result of the data analysis rejected the research hypotheses. Accordingly, we concluded that the null hypothesis 1 was rejected and there is a positive relationship between accommodating learning style and the students' self-regulation. Since according to Perry, Phillips \& Hutchinson, (2006) self-regulated learners believe success in learning occurs when a person always keeps practicing, having well understanding of topics and putting hard effort, and accommodating learners enjoy trial and error and consider learning experimentally, and look for act-based opportunities therefore the positive relationship between them is justifiable. The second null hypothesis was rejected and there is a positive relationship between converging learning style and the students' self-regulation. Since self-regulation provides learners with a role in decision making and offers a supportive approach of learning (Man-Chih, 2006) it is in accordance with converging learners' characteristics because they tend to make decisions and are considered as problem solvers and decision makers. The correlation coefficient between divergent learning style and students' self-regulation is significant over \%1 level hence the null hypothesis 3 is also rejected and this finding that reveals a positive relationship between diverging learning style and self-regulation. Self-regulated learners according to (Lavasani et al, 2011) put metacognitive strategies into use to get advantage of learning process, and this is in line with the feature of the diverging learners who are thoughtful and have strong imagination, and consider one experience or event from different aspects. Finally, by the correlation coefficient between assimilating learning style and students' self-regulation, we can conclude 
that the null hypothesis 4 was rejected and there is a positive relationship between assimilating learning style and the student's self-regulation. According to Paris \& Paris (2001) self-regulated learners put emphasis on monitoring, directing and regulating actions to achieve goals, increase ability and improve knowledge, these characteristics are in line with assimilating learners' feature that they prefer to participate in learning, by studying and reflecting.

The present study concentrated on only female learners and only in one city that is Mashhad. It can give different results if it is done as future research on both genders and on learners with different cultural background and age. Therefore incorporating such data may strengthen the result of the study.

More research may be done to examine the relationship between self-regulation and motivation. Specially, there may be the need to evaluate if self-regulation affect the learners' motivation.

\section{References}

Bandura, A., \& Zimmerman, B. J. (1994). Impact of self-regulatory influences on writing course attainment. American Educational Research Journal, 4, 845-862.

Brown, H. D. (2007). Teaching by principle, an interactive approach to language pedagogy. The United States: Pearson Longman.

Butler, D. L., \& Winne, P. H. (1995). Feedback \& Self-regulated learning. A theoretical synthesis. Review of Educational Research 65, 245-281.

Dasta, H. (2007). A study on the relationship between the university students' self-regulation and moral judgment (unpublished master's thesis). Islamic Azad University, Marand branch, Iran.

D'amore, A., James, S., \& Mitchell, E. K. (2011). Learning styles of first-year undergraduate nursing and midwifery students: A crosssectional survey utilizing the Kolb Learning Style Inventory. Nurse Education Today 32(5), 506-15.

Dobson, J. L. (2009). Learning style preferences and course performance in an undergraduate physiology class. Adv Physiol Education, $33(4), 308-14$.

Dweck, C. S., \& Leggett, E.L. (1988). A social cognitive approach to motivation and personality. Psychological Review 95, 256-273.

Dweck, C. S., (2002). Beliefs that make smart people dumb. In R. J. Sternberg (Ed.), Why smart people do stupid things. New Haven: Yale University Press.

Felder, R. M. \& Silverman, L. K. (1988). Learning \& Teaching Styles in Engineering Education. Journal of Engineering Education, 78(7), 674-681.

Goldleski, E. S. (1984). Learning Style Compatibility of Engineering Students and Faculty. Proceedings, Annual Frontiers in Education Conference. ASEE/TEEE, Philadelphia, 362.

Kolb, A. Y., \& Kolb, D. A. (2005). The Kolb learning style inventory-version 3.1. Experience Based Learning Systems, 30-70.

Kolb, D. (1984). Learning styles model and experiential learning theory. Retrieved from http://www.businessballs.com /kolblearningstyles.htm

Lavasani, M. G., Mirhosseini, F. M., Hejazi, E., \& Davoodi, M. (2011). The effect of self-regulation learning strategies training on the academic motivation and self-efficacy. International Conference on Education and Educational Psychology, 29, 627-632.

Man-Chih, A. (2006). The effect of the use of self-regulated learning strategies on college students' performance and satisfaction in physical education (Doctoral thesis, Australian Catholic University). Retrieved from http://researchbank.acu.edu.au/theses/160

Norman, G. (2009). When will learning style go out of style? Adv Health Education Theory Practice. 14(1), 1-4.

Ormrod, J.E.,(2009). Principles of Educational Psychology. Canada: Pearson Education.

Palincsar, A. S., \& Brown, A. L. (1984). Reciprocal teaching of comprehension fostering and comprehension monitoring activities. Cognitive and Instruction 1(2), 117-175.

Paris \& Paris, A. (2001). Classroom Application of Research on Self-regulated Learning. Educational Psychologist. 36(2), 89-101.

Perry, N.E., Phillips, L., \& Hutchinson, L.R. (2006). Preparing student teachers to support for self-regulated learning. Elementary School Journal, 106, 237-254.

Peters, J., (2009). Responsive, reciprocal relationships: The heart of the Te Whariki curriculum. In T. Papatheodorou, \&J. Moyles (Eds.), Learning together in the early years: Exploring relational pedagogy (pp. 23-32). Oxon, United Kingdom: Routledge.

Pintrich, P. R. (2000). Multiple goals, multiple pathways: the role of goal orientation in learning and achievement. Journal of Education Psychology, 92, 544-555.

Pintrich, P. R., \& De Groot, E. V. (1990). Motivational and self-regulated learning components of classroom academic performance. Journal of Educational Psychology, 1, 33-40.

Pintrich, P. R., \& Schunk, D. H. (2002). Motivation in education: theory, research, and applications. Upper Saddle River, NJ: MerrillPrentice Hall.

Rakes, G. C., \& Dunn, K. E., (2010). The impact of online graduate students' motivation and self-regulation on academic procrastination. Journal of Interactive Online Learning, 86-89.

Winne, P. H., \& Perry, N. E. (2000). Measuring self-regulated learning. In P. Pintrich, M. Boekaerts, \& M.seidner (Eds.), Handbook of self-regulation. Orlando, FL: Academic Press. 